\title{
Revisiting the Phonology and Morphosyntax of Chechen and Ingush Verb Doubling
}

\author{
RYO MASUDA \\ Massachusetts Institute of Technology*
}

\section{Introduction}

The study of clitics has been a fertile site for investigating matters of the syntax-phonology interface, arguably second only to phonological phrasing phenomena. For instance, a classical puzzle has been the analysis of Wackernagel clitics, which appear in a second 'position' in the clause, either following the first syntactic phrase or first stressed word (Wackernagel 1892). Recent work have converged on an integrated model, whereby the implementation of clitic placement is distributed across both the syntactic and post-syntactic (PF) components of the grammar (Bošković 2001; Mavrogiorgos 2013; Spencer \& Luís 2012). Bošković's (2001) manuscript presents an overview of the field at the time, ranging from strongly syntactic approaches to strongly phonological approaches, and based on data from cases such as Serbo-Croatian clitics, argues against these unilateral analyses. A natural question that follows from this conclusion is to what extent these two components may be divorced: if syntactic operations such as movement and PF mechanisms such as phonological filters are independent, then we may expect instances where the syntax is relatively inert while the PF component remains active.

Ingush and Chechen, two Northeast Caucasian languages, demonstrate a rare interaction between cliticization and word-level reduplication. In these languages, a clitic ' $a$ appears homophonously in a number of contexts, among them as a clause chaining marker. The conventional definition for a chained clause is a coordinated clause which shares the subject with the other conjunct. The languages exhibit OV word order and the verb phrase may also include preverbal elements (such as light verb constructions) and deictic markers. In chained clauses with transitive verbs (1) or other qualifying preverbal elements (2-3), the clitic ' $a$ is hosted by the immediately preverbal item. Data come from Good (2005) and Nichols (2011).

(1) Ahwmad, zhwala 'a iacna, vilxira

Ahmed dog \& buy.CVANT cry.WP

'Ahmed bought a dog and cried.' / 'Ahmed, having bought a dog, cried.'

(2) Complex verb constructions

a. Ahwmada, kiexat jaaz 'a dina, zheina dueshu Ahmed.ERG letter write \& do.CVANT book read.PRES

'Ahmed, having written a letter, reads a book.'

\footnotetext{
*I am thankful to Brian Agbayani, Adam Albright, Michael Kenstowicz, Norvin Richards, Donca Steriade, the audiences of BLS40 and the Phonology Circle at MIT (Nov 2013), and the editors and reviewers of this proceedings volume for comments and discussion.
} 
b. Maliika loomax hwal 'a jeelara ohwa 'a joessara.

Malika mountain.LAT [up \& go.WP] [down \& descent.wP]

'Malika went up and down the mountain.'

(3) Maliikas Ahwmadna zheina dwa 'a della, dw jaghara

Malika.ERG Ahmed.DAT book DX \& give.WP DX go

'Malika gave the book to Ahmed and left.'

In an intransitive simplex verb, which lacks an appropriate preverbal host, the infinitival form of the verb appears to the left of ' $a$ (and the finite verb) to host the clitic:

(4) Ahwmad, wa='a wiina, dwa-vagh-ara.

Ahmed stay.inf $=\&$ stay.acv deix-go-past

'Ahmed stayed (for a while) and left.' [Chechen]

We henceforth refer to this case of word-level reduplication as verb doubling. The particle ' $a$ has previously received some attention due to its typologically rare requirement for a phonological host that is in the opposite direction from its syntactic affiliate - a ditropic clitic under Embick \& Noyer's (1999) classification (Klavans 1985; Cysouw 2005; Peterson 2001), and limited work has been done on capturing the cliticization and verb doubling phenomenon (Good 2005; Conathan \& Good 2001).

In this paper, we revisit the Chechen and Ingush ' $a$ and advance the proposal that the clitic and its interaction with verb doubling are implemented exclusively in the postsyntactic component, under morphological and prosodic considerations. We demonstrate that the various aspects of the Chechen and Ingush data have close parallels to other effects analyzed as arising from PF operations, and contrast them to instances under the effect of syntactic operations. In so doing, we expand the attested range of cliticization phenomena while showing that this rare case still falls within the expected typology.

The paper proceeds as follows: In $\S 2$ we discuss further data from Chechen and Ingush, highlighting three typologically rare aspects of the phenomenon that any theory of cliticization must capture. In $\S 3-4$ we present previous phonological and morphosyntactic approaches to the cliticization and verb doubling facts and discuss shortcomings of the proposals. In $\S 5$ we present a revised morphophonological analysis and discuss its theoretical ramifications and accounts for the typology of cliticization.

It must be emphasized that we do not distinguish between Ingush and Chechen with regards to coordination. This is supported by similar claims by Good (2005) and Jeschull (2004). However, future work would include teasing apart the differences in their coordination constructions.

\section{Typological issues with Chechen/Ingush 'a}

There are three aspects of the particle ' $a$ and its associated verb doubling phenomenon that are considered typologically rare. In this section we present these in turn, then return to these aspects in further sections in developing an analysis. 


\subsection{Ditropic clitic}

Fieldwork reports on Chechen and Ingush have characterized 'a as an enclitic based on traditional diagnostics for cliticization. However, since it serves as a clause chaining clitic, its syntactic affiliate is with the finite verb to its right. ${ }^{1}$ We do not expect the infinitival verb to be the syntactic affiliate, as we have seen that its position as a phonological host is equally satisfied by non-verbal elements. Thus we have the following schematic for ' $a$.

(5) $[$ Host $]=' a \mathrm{~V}$

This configuration has been characerized as a ditropic (two-placed) clitic by Embick \& Noyer (1999). A typical clitic is non-ditropic, e.g. English 's which appears to the right of and is phonologically hosted by the affiliated noun phrase:

(6) $[\mathrm{DP}]=' \mathrm{~s}$

Ditropic clitics have been controversial in the literature. While Klavans's (1995) influential typology of clitics treated ditropic and non-ditropic clitics equally, subsequent work such as Embick \& Noyer (1999) have argued for a more restrictive characterization of clitics based on the paucity of attested ditropic cases. A recent survey by Cysouw (2005) further reaffirms the rarity of ditropic clitics and the potential for such configurations to be epiphenomenal.

\subsection{Verb doubling is vacuous}

Word-level reduplication is commonly attested cross-linguistically as serving a functionally iconic or emphatic role. For example, the Atlas of Pidgin and Creole Language Structures (APiCS) project has categorized reduplication into the following categories, a classification in which the symbolic uses (iconic and attenuating) receive primary status.

(7) a. Iconic reduplicaton: Denotes "iteration, plurality, distributivity, and/or intensity."

b. Attenuating reduplication: Serving a role similar to -ish suffixation in English.

c. Word-class changing reduplication

d. Other uses

English, which is impoverished of morphological reduplicaton processes compared to other languages, still exhibit phrasal iconic reduplication (Ghomeshi et al. 2004).
a. Intensive reduplication
It's mine, mine, mine!
b. Verbal contrastive reduplication
Do you LIKE-like her?
c. Nominal contrastive reduplication
I don't want a TUNA salad, I want a SALAD-salad.

Good (2005) argues that verb doubling in Chechen does not fit this semantic or pragmatic profile of symbolic reduplication. If this is so, then such a vacuous instance of reduplication at the phrasal level is cross-linguistically rare.

\footnotetext{
${ }^{1}$ Alternatively, the syntactic affiliate is the entire clause. However, we must then still account for why it appears internal to its affiliate.
} 


\subsection{A lexical host is inserted for cliticization}

Clitics have the capacity to be mobile. In Polish, agreement clitics exhibit promiscuous attachment (Spencer \& Luís 2012:85), taking as its host most preverbal stressed elements.
a. Ja to robile $=\mathrm{m}$
I it $\operatorname{did}=1 \mathrm{SG}$
'I did it'
b. Ja to $=\mathrm{m}$ robil

Further, consider the Tobler-Mussafia languages (Tobler 1875; Mussafia 1888); a set of languages in which pronominal clitics are immediately preverbal (10a) unless this places them in initial position (10b), in which case it becomes immediately postverbal (10c). Examples are from Franks and Bokovi (2001:174).
a. Včera mi go dade Petko. yesterday me.DAT it.ACC gave Petko
'Yesterday Petko gave it to me.'
b. * Mi go dade Petko včera. me.DAT it.ACC gave Petko yesterday 'Yesterday Petko gave it to me.'
c. Dade mi go Petko včera. gave me.DAT it.ACC Petko yesterday

In contrast, the related Slavic language of Macedonian permits initial clitics, and bans postverbal clitics. Thus Macedonian "fails to repair" the initial clitic cluster. ${ }^{2}$

The table below summarizes the variety in cliticization. While each of the phenomena discussed above have been broadly attested cross-linguistically with variation, verb doubling is a distinct, rare mechanism for satisfying a requirement on clitic placement that must be accounted for in any theory of cliticization.

Clitic positioning strategies

\begin{tabular}{ll}
\hline Clitic process & Example \\
\hline Relatively free movement to hosts & Polish \\
Movement to 2nd position & Wackernagel languages \\
$\begin{array}{l}\text { Movement to 2nd position only } \\
\quad \text { if otherwise initial }\end{array}$ & Tobler-Mussafia languages (Bulgarian) \\
No repair & Macedonian \\
Verb doubling & Ingush and Chechen \\
\hline
\end{tabular}

\footnotetext{
${ }^{2}$ We are wording the discussion as if it were a phonological constraints-and-repairs problem, but this should be taken to be a descriptive generalization. Franks \& Bošković (2001) provide compelling evidence that the Tobler-Mussafia effect is sensitive to syntactic properties.

${ }^{3}$ Although we exclusively discuss doubling of verbs, the theory does not immediately preclude reduplication of this sort from applying to other lexical categories.
} 


\section{Syntactic considerations}

There have been two prior approaches for verb doubling and cases of syntactic reduplication in general. We discuss issues that such analyses encounter when applying them to Ingush and Chechen.

\subsection{Verb doubling as movement}

Under the copy theory of movement, verb doubling may be analyzed as the pronunciaton of both copies of a verb which has undergone movement. For example, consider predicate clefting data from Vata (Koopman 1984). In (12a), a focused verb is reduplicated at the left periphery. A similar effect is obtained in (12b), but under the presence of the auxiliary $d a$, the verb appears lower in the clause.
a. li à li-da zué saká
eat we eat-PAST yesterday rice
'We ATE rice yesterday.'
b. li O da saká li
eat she/he PERF-AUX rice eat
'She/he has EATEN rice.'

Nunes (2004) analyzes the data as an instance of a verb that has moved from its TPinternal position to a higher focus projection (13a). If an auxiliary is present, movement of the main verb to $\mathrm{T}$ does not occur and the secondary trace of the verb that is pronounced is in its base position (13b). ${ }^{4}$
a. $\left[\right.$ FocP $\left.\mathrm{V}^{0}+\mathrm{Foc}^{0}\left[\mathrm{TP}\left\langle\mathrm{V}^{0}\right\rangle+\mathrm{T}^{0}\left[\mathrm{VP} \ldots\left\langle\mathrm{V}^{0}\right\rangle \ldots\right]\right]\right]$
b. $\left[\right.$ FocP $\left.\mathrm{V}^{0}+\operatorname{Foc}^{0}\left[\mathrm{TP} \mathrm{T}^{0}\left[\mathrm{VP} \ldots\left\langle\mathrm{V}^{0}\right\rangle \ldots\right]\right]\right]$

Movement-based analyses have also been invoked for clitic positioning. Recall the ToblerMussafia languages discussed in $§ 2.3$, which we reproduce here: in Bulgarian, pronominal agreement clitics usually occupy the immediately preverbal position (14a) with no intervening elements (14b). Example (14c) shows that they are not second position clitics.
a. V̌era mi go dade Petko.
yesterday me.DAT it.ACC gave Petko
'Yesterday Petko gave it to me.'
b. * Petko mi go včera dade.
Petko me.DAT it.ACC yesterday gave
c. V̌cera Petko mi go dade. yesterday Petko me.DAT it.ACC gave

\footnotetext{
${ }^{4}$ Similar analyses has been proposed for verb doubling in Mandarin Chinese (Cheng 2007) and in Nupe (Kandybowicz 2008). These are not the most direct applications of the copy theory of movement: Nunes considers the higher verb copy to be part of an independent chain that arises from morphological merger of the verb with the focus head. Hence the two overt copies of the verb are not due to pronunciation of both links in a movement chain, but rather due to pronunciation of links in two different chains.
} 
When the clitic-verb complex is sentence-initial, the clitics switch to the immediately postverbal position.

$$
\begin{aligned}
\text { a. } & * \text { Mi go dade Petko včera. } \\
& \text { me.DAT it.ACC gave Petko yesterday } \\
& \text { 'Yesterday Petko gave it to me.' } \\
\text { b. } \checkmark & \text { Dade mi go Petko včera. } \\
& \text { gave me.DAT it.ACC Petko yesterday }
\end{aligned}
$$

Franks \& Bošković (2001) analyze the clitics as undergoing movement to a higher position in the $\mathrm{CP}$ domain, creating a movement chain. If the higher position is ruled out by the postsyntactic requirement on non-initiality of clitics, then it is the lower copy in the base position that is pronounced. If it is not initial, then the higher (pre-verbal) copy is pronounced based on general principles of pronounciation of chains.

\subsection{Verb doubling as anstract emphatic element}

A recent development in accounts of verb doubling is the introduction of an abstract morpheme whose phonetic realization requires reduplication. Kimper (2008) discusses the work on syntactic reduplication via pronunciation of movement chains as presented above and discusses the shortcomings of an analysis in which doubling and alternations only arise from a choice in pronunciation of chains. Kimper proposes that what is driving movement is a reduplicative morpheme, and the form in doubling constructions do not match because they belong to the same movement chain but rather because the reduplicative morpheme enforces similarity in its pronunciation.

Kimper does not make explicit what exactly can introduce the reduplicative morpheme into the syntactic derivation, but all of the examples involve some sort of intensification, focus, or emphasis, and he writes: "In syntactic reduplication, some semantic meaning is realized by copying of some syntactic constituent" (emphasis mine). Such a link to semantic content is also true for the class of analyses which utilize the copy theory of movement: a focus or emphasis position or a focus element which triggers morphosyntactic operations is present in them. Indeed, 'a does appear in cases where focus is present: Peterson (2001) reports that the clitic is used for concessive emphasis, as in (16a), or in non-verbal focus, as in (16b). However, we see in both examples that they pattern with nominal coordination uses of ' $a$ (16c) in being final: after either the verb or the entire concessive clause in the first case, and after the focused element in the second case.

a. Ajšiet j-iilx-ača='a Muusaa v-ax-anz-ar.

Aisha AGR-cry.TRCV='a Musa AGR-go-NEG-PAST

'Even when Aisha cried, Musa didn't go.'

b. Ahmad, sialxana='a wiina, dwa-vagh-ara.

Ahmed yesterday $=$ FOC stay.ACV DEIX-go-PAST

'Ahmed stayed YeSTERDAY and left.' 
c. Ha'a, louzar='a, biegazh='a myshta xular joax hwaalxagh?

yes dance='a games='a how be.IMP QUOT formerly

'Yes, what kinds of dances and games were there formerly?'

Therefore, if syntactic operations are being triggered by focus or emphasis, it must be localized to the clausal coordinating context with the presence of ' $a$, i.e., the context where native speakers report no emphatic force.

One caveat is that focus and verb doubling do co-occur, optionally, in the context of emphatic negation in Chechen and Ingush:

$$
\begin{aligned}
& \text { (aala) ma aala! } \\
& \text { say.INF NEG say.INF } \\
& \text { 'Don't (even) tell!' }
\end{aligned}
$$

The distribution of ' $a$ and verb doubling within the languages does suggest a diachronic pathway towards the current system. First, perhaps ' $a$ as a coordinating particle did have the syntax and semantics of emphasis. For example, Ohori (1992) suggests that among the clause chaining elements in Japanese, two of them seem to only differ in whether it encodes emphatic assertion.

(18) Samui node/kara kaze-o hiita.

cold because flu-ACC get.PAST

'Because it is cold, I caught the flu.'

Jinkō-ga antē suru-to kēzai-ga hattatsu suru.

population-NOM stable do-then economy-NOM develop do

Iya, kēzai-ga hattatsu suru-kara/??node jinkō-ga antē suru.

no economy-NOM develop do-KARA/NODE population-NOM stable do

'When the population stabilizes, the economy will take off. No, it is precisely because the economy takes off, the population stabilizes.'

Although we see in (18) a nearly equivalent meaning between kara and node being obtained, in cases such as (19) where the emphatic force is brought forward in the discourse, node is strongly dispreferred in favor of kara. Hence a diachronic link between emphasis and clause chaining appears at least tenable.

We posit that the departure of ' $a$ in its position from the other uses of ' $a$ arose from prosodic considerations which we elaborate in further sections. Verb doubling as a repair may have arisen as a syntax-phonology interaction along the lines of more traditional cliticization phenomena, which was later reanalyzed following the loss of emphatic force in the coordinating construction.

To conclude, previous analyses that use syntactic mechanisms to account for verb doubling have exploited the semantics of focus. Such an analysis must reconcile the absence of similar effects in actual focus contexts in Chechen and Ingush. We therefore advance an alternative in which verb doubling has been reanalyzed as a morphological operation which is activated under prosodic considerations. Before presenting our analysis, we first discuss a previous prosodic analysis. 


\section{Towards a prosodic analysis: Good (2005)}

Good (2005) proposed a phonological template that accounts for the Chechen and Ingush facts. We present it here and discuss issues of overgeneralization.

The basis for Good's analysis lies in a comparison to prosodic minimality phenomena at the word level. In a number of languages, words must have a minimal number of syllables, and further, it is often the case that reduplication is employed to satisfy such a requirement. Good discusses two cases from the Bantu family. The first is from Ndebele: imperatives are generally formed with the bare verb stem and a theme vowel.
a. lim-a 'cultivate!'
b. bamb-a 'catch!'
c. thum-a 'send!'

However, if the stem is -C- or -CC-, then the imperative construction would be monosyllabic. To avoid this, an empty morpheme $y i$ - is prefixed:
a. yi-z-a
'come!' *z-a
b. yi-dl-a 'eat!' *dl-a
c. yi-lw-a 'fight!' *lw-a

Similarly, consider the case of Ciyao (Ngunga 2000). In this language, it is the morpheme which must be minimally disyllabic. Perfectivity, which is expressed through reduplication, may result in further reduplication to satisfy this requirement.
a. diile-diile 'eat.PERF'
b. wiile-wiile 'die.PERF'
a. taataa-ta 'name.PERF' *ta-ta
b. waawaa-wa 'die.PERF' *wa-wa

Thus Good analyzes verb doubling as a consequence of a similar minimality requirement, but at the phrasal level. Whereas the Bantu facts represent a constraint of $\omega \geq \sigma \sigma$, where every phonological word must at least be disyllabic, under Good's analysis, there is a constraint $\varphi \geq \omega \omega$, where every phonological phrase must have at least two words, active in Ingush and Chechen.

The immediate issue which Good encounters is that uncoordinated intransitive verbs may stand alone.
So voelu.
I laugh.PRES
'I am laughing.'

When such a verb is coordinated, the verb is in a subminimal phonological phrase, the subject cannot host the clitic ' $a$, and verb doubling is triggered. One proposal is that uncoordinated intransitive verbs are defective and that they can form a phonological phrase with the subject, satisfying the phrasal minimality constraint. The alternative which Good argues for is that the minimality requirement is subject to a non-derived environment blocking (NDEB) condition. As an analogue, consider the process of velar deletion in Turkish 
(Inkelas 1998). If a vowel-initial suffix such as the accusative and dative markers cause a stem-final velar to appear intervocalically, then the velar is deleted, as in (25). However, stem-internal intervocalic velars are permitted (26). Example (26b) shows both cases: the stem-internal $g$ is preserved but the stem-final $k$ is deleted under affixation.

$$
\begin{aligned}
& \text { a. bebek 'baby' katalog 'catalog' } \\
& \text { b. bebe-i 'baby.ACC' katalo-u 'catalog.ACC' } \\
& \text { c. bebe-e 'baby.DAT' katalo-a 'catalog.DAT' } \\
& \text { a. guguk 'cuckoo call' *guuk } \\
& \text { b. gugu-a 'cuckoo call.DAT' } \\
& \text { *guu-a }
\end{aligned}
$$

Hence some phonological processes may only apply to derived environments such as at affixation boundaries. Good posits that such an effect may be observed with phrasal processes as well. He defines the notion of a derived constituent: "A syntactic constituent can be said to be phonologically derived if syntactic requirements force the inclusion of phonological material into the constituent which alters its prosodic structure." As the clitic is presumed to have a position in the syntactic derivation, it generates a derived environment which activates the phrasal minimiality constraint.

Good's analysis predicts that the proposed extensions to phrasal phonology, namely templatic effects and non-derived environment effect sensitive to syntactic operations, ought to be robustly attested independently of cliticization contexts. However, he leaves the latter as an empirical issue, and the only example that Good cites for phrasal templates is Inkelas and Zec (1990) on Serbo-Croatian. There, a topicalized first name is said to be ruled out by phrasal minimality (27a) while larger constituents (27b-27c) are permitted.

$$
\begin{array}{ll}
\text { a. * } & \text { Petar voleo-je mariju } \\
& \text { Peter loved-Aux Mary.ACC } \\
& \text { 'Peter loved Mary.' } \\
\text { b. } \quad \text { [Taj čovek] voleo-je mariju. } & \text { that man.NOM loved-Aux Mary.ACC } \\
& \text { 'That man loved Mary.' } \\
\text { c. } \quad \text { [Petar Petrović] voleo-je mariju. } & \text { Peter Petrovic loved-Aux Mary.ACC } \\
& \text { 'Peter Petrovic loved Mary.' }
\end{array}
$$

The analysis is also deficient in failing to account for the number of typological considerations surrounding the cliticization and verb doubling phenomena. It is left coincidental that the templatic effect, which already lacks empirical precedent, is applied to a particle belonging to the rare class of ditropic clitics. Further, Good must stipulate that the template only applies to the phonological phrase associated with the VP. While we remain neutral on the general question of whether phonological phrasing is sensitive to such fine details of the syntactic architecture, we will claim that asymmetries between the phrasing of standarad verb phrases and other phrases are sufficient to account for the Ingush and Chechen facts. 
It is indeed an empirical issue to find phenomena in other languages which may rule in favor of extending the word-level phonology to the phrasal domain. However, we will present a more restrictive analysis that utilizes mechanisms which have been more robustly used and simultaneously accounts for more of the typological considerations.

\section{Morphophonological analysis}

We now advance our alternative PF account of cliticization and verb doubling in Chechen and Ingush. Based on grammatical descriptions of Chechen utterances, it appears likely that the verb phrase invokes a phrasing in which the phrasal stress is non-final, and general prosodic constraints on cliticization are the motivation for the processes seen in the data.

\subsection{Prosodic considerations}

Mobility of clitics and their sensitivity to edges and phrasal 'weight' are well-attested we have already seen edge-related phenomena in the Wackernagel and Tobler-Mussafia languages, and promiscuous attachment in Polish due to stress.

Another instance of stress sensitivity of clitics is in German, where a weak set of clitics are restricted in its distribution. Such clitics may not appear in a stressed position:

(28) Wen hast du gesehen? [zi:]/*[ze].

who have you seen 3SG.FEM.ACC

'Who have you seen? Her.'

Additionally, weak clitics must be hosted by a strong phonological host such as a preposition. In (29a) we see that the clitic may alternate with a freestanding word after mit, but lacking such a host, the weak clitic is ruled out (29b).
a. Wir haben mit $[\mathrm{dem} / \mathrm{m}]$
Franz darüber geredet
we have with DEF.MASC.SG.DAT Franz about.it spoke
'We spoke with Franz about it.'
b. $* \mathrm{M} \quad$ Kind hat sie eine Geschichte erzahlt
DEF.NEUT.SG.DAT child has she one story told
'She told the child a story.'

Like the previous cases, we propose that the positioning of the clitic before the verb in conjoined clauses of Chechen and Ingush is also due to prosodic conditions. In support of this proposal, we cite Nichols's (2011) grammar of Ingush. In it, she reports: "the last two accentable words [in any phrase or clause] constitute a part of of an intonational phrase," with the penultimate element receiving primary stress. We note that Good's analysis does not directly invoke the general tendency for weight attraction of clitics.

It follows that a coordinated phrase with ' $a$ also has penultimate stress. Then the clitic is attracted to the penultimate element as a host, either due to weight considerations or due to phrasal edge avoidance. Further work is necessary to adjudicate between these two approaches. 
Consideration of the mapping between syntax and phonological phrasing enables us to posit why it is only the conjoined clauses which exhibit this preposing of the clitic. Crucially, we have seen that nominal coordination and ' $a$ as a focus marker do not exhibit the ditropic behavior - it may appear at the right edge of the phrase and procliticize to the item to its left.

$$
\begin{aligned}
& \text { Ha'a, louzar='a, biegazh='a myshta xular joax hwaalxagh? } \\
& \text { yes dance='a games='a how be.IMP QUOT formerly } \\
& \text { 'Yes, what kinds of dances and games were there formerly?' }
\end{aligned}
$$

As focused elements are assigned exceptional prosody cross-linguistically, it should not be surprising that it would bear stress that can serve as a site for clitic hosting. Nominal coordination is more trouble-some to a prosodic analysis in the absence of acoustic data. Jeschull (2004) reports that nominal coordination may be implemented without ' $a$ but with comma intonation, in which the first syllable of the coordinand receives stress. It is an empirical question whether there is exceptional prosody for coordinated nominals which differ from chained clauses.

\subsection{Morphophonological considerations}

We have demonstrated that there are difficulties in implementing the realization of the doubled verb in the syntactic component. We thus advance the claim that the verb doubling is also post-syntactic in nature, implemented purely in the morphological component of the grammar. We invoke a theory of morphophonology that integrates the two aspects - that of Optimal Interleaving (Wolf 2008). The analysis does not crucially rest on this particular theory, and in particular, we will not discuss the Candidate Chains aspect of Wolf's model. However, we find theoretical value in the fact that the Chechen and Ingush data is but one of a number of phenomena that have been analyzed in a single framework, rather than needing to propose drastic changes to the theory as is the case with Good's (2005) previous analysis. In particular, in the next section we will show another example of a cliticization process in K̄̄sêdjê which has been analyzed under the Optimal Interleaving framework.

The principal notion of the model is that morphological exponence and evaluation of phonological constraints are performed within the same framework. Quoting Wolf: "morphological spellout (Halle \& Marantz 1993's 'vocabulary insertion') occurs in the phonological component of the grammar.' Hence morphological processes may be influenced by the phonology and vice versa. This is of course not a new idea, as it has its roots in earlier work on Lexical Phonology and Morphology (Kiparsky 1982, Mohanan 1982).

The Wolf-style constraints that I posit are as follows.

(31) a. $\operatorname{DEP}(\mathrm{M})$ : Every morpheme in the output must have a correspondent in the input.

b. $\operatorname{Max}(\mathrm{M})$ : Every morpheme in the input must have a correspondent in the output.

c. ONECOPY: If a morpheme in the input has multiple correspondents in the output, assign a violation for each one after the first.

d. FAIth $(\mathrm{Cl})$ : A proclitic (resp. enclitic) in the input must be a proclitic (resp. enclitic) in the output. 
e. ClStress: Clitics must be hosted by a phrasally stressed element.

Under Good's analysis, the inertness of the phrasal template for simple intransitive verbs in non-coordinated contexts were accounted for by non-derived environment blocking. With our analysis, a syntactic structure without the coordinating clitic 'a does not interact with any of the relevant clitic constraints, and hence surfaces faithfully, i.e., without movement or insertion of a doubled verb.

Now let us consider the case where a simplex verb is doubled under a coordinated clause.

Conjoined intransitive verb

\begin{tabular}{|l|c|c|c|c|c|}
\hline Verb='a & CLToStRess & FAith(CL) & MAx(M) & DeP(M) & ONECopY \\
\hline a. Verb='a & $* !$ & & & & \\
\hline b. 'a=Verb & $(* !)$ & $* !$ & & & \\
\hline c. '=a Verb & $* !$ & & $*$ & & \\
\hline d. Verb & & & $* !$ & & \\
\hline e. Expletive='a Verb & & & & $* !$ & \\
\hline f. > Verb='a Verb & & & & & $*$ \\
\hline
\end{tabular}

The verb alone cannot host the clitic 'a because the clitic would either be final in its phrase (a) or not right-aligned in its word (b), ruling out the first two candidates. A clitic cannot be free-standing, ruling out candidate (c). $\operatorname{MAx}(\mathrm{M})$ militates against outputs which fail to realize a morpheme from the input, so the clitic-less candidate (d) is ruled out. Finally, we crucially have $\operatorname{Dep}(\mathrm{M})$ and OneCopy: the latter is sensitive to an output in which a morpheme has multiple exponents, as in verb doubling, but the former is only violated with an exponent without a corresponding input. As a consequence, the ranking $\operatorname{DEP}(\mathrm{M})>>$ ONECOPY rules out the candidate with an inserted expletive in favor of the candidate with a doubled verb.

The above tableau demonstrates the interaction of a primarily prosodic constraint such as CLToStress with a more general constraints on morphological exponence $(\operatorname{DeP}(\mathrm{M})$ and $\operatorname{Max}(\mathrm{M}))$.

Next, consider the case of a transitive verb with its object or another preverbal element, which we denote by Host. This element is in the input form, and hence no violation of DeP via verb doubling is necessary to satisfy the high-ranking constraints on clitic placement.

Conjoined Transitive Verb (also Preverbal constructions)

\begin{tabular}{|l|c|c|c|c|c|}
\hline Host Verb='a & CLToStRess & FAIth(CL) & MAX(M) & DeP(M) & ONECopy \\
\hline a. Host Verb='a & $* !$ & & & & \\
\hline b. Host 'a=Verb & $* !$ & $* !$ & & & \\
\hline c. $>$ Host='a Verb & & & & & \\
\hline d. Host Verb='a Verb & & & & & $* !$ \\
\hline
\end{tabular}

Finally, we consider the case where both an object and a preverbal particle is present. Recall that in such a case, it is the preverb and not the object that hosts the clitic. This is not surprising under the prosodic approach, as the preverb would always receive the phrasal stress as it is in penultimate position. 
Conjoined Transitive Verb with Preverb

\begin{tabular}{|l|c|c|c|c|c|}
\hline a. Obj PV Verb='a & CLToStress & FAith(CL) & MAX(M) & DeP(M) & OneCoPY \\
\hline b. Obj PV Verb='a & $* !$ & & & & \\
\hline c. Obj PV 'a=Verb & $* !$ & $* !$ & & & \\
\hline d. $>$ Obj PV='a Verb & & & & & \\
\hline e. Obj='a PV Verb & $* !$ & & & & \\
\hline
\end{tabular}

\subsection{Infinitival form of the verb}

The previous tableaux did not show inflectional features on the verb, which are certainly relevant because the doubled verb is infinitival while the original verb need not be. If we are to interpret the verb doubling in Chechen and Ingush as arising purely from the PF component, we require a model of the grammar which can access morphological variants at the point of prosodification. This may be a controversial step to take. However, we argue that it is still a weaker modification to the model than those which posit syntactic operations which are sensitive to phonological constraints.

\section{Some typological implications}

The grammar as modeled under this analysis has components which interact but are largely independent of one another. Thus we predict other cross-linguistic data which fall under this general umbrella of doubling and/or cliticization which are similar to the data observed in Chechen and Ingush. We present some evidence for this below.

\subsection{Ditropic clitics are rare}

The distribution of the coordinating clitic ' $a$ is consistent with the claim by Cysouw (2005) and others that ditropic clitics are epiphenomenal and hence rare. In Chechen and Ingush, it arose due to a particular interaction of constraints: non-finality/stress attraction of clitics, low-ranked restriction on multiple exponence, and faithfulness to the clitic's status as an enclitic. The first constraint appears to be readily dominated, as we see that 'a can quite commonly appear to the right of its host at the edge of (syntactic) phrases. The last constraint, when violated, would enable a clitic to behave as in the finiteness sensitive languages. In either scenario, we are left with a non-ditropic clitic.

\subsection{Clitics are sensitive to morphological faithfulness}

In incorporating aspects of Wolf's morphophonological framework, we are lead to posit that clitics may be evaluated for $\operatorname{MAx}(\mathrm{M})$, that it remain in the output if it is present in the intermediate output of the syntactic component. Evidence that such a constraint interacts with more purely phonological constraints is provided by Nonato (2013) on Kīsêdjê (Jê, Brazil).

In Kīsêdjê, plurality is marked by a clitic $=a j$ which appears to the right of nominative pronouns and to the left of accusative and absolutive pronouns. Thus in sentences with a 
plural subject and plural object we expect two instances of $=a j$, as in (35).

"hẽn=wa $\quad$ "kê=aj $\quad \varnothing-" k h a ̃ m=a j$ s-õmu

$\mathrm{INFL}=1 . \mathrm{NOM}$ also $=\mathrm{PL} 3 . \mathrm{ABS}-\mathrm{in}=\mathrm{PL} 3 . \mathrm{ACC}-\mathrm{see}$

'We also saw them there.'

In the above example, there is a stressed preposition khãm that intervenes between the two plural clitics. The language disprefers sequences of unstressed elements, and so the construction without an intervening stressed word is ungrammatical (36a). Instead, only one plural marker is realized, and it is three-way ambiguous between plural subject+object, subject, or object (36b).

$$
\begin{aligned}
& \text { a. * "hẽn=wa "kêeaj=aj s-õmu } \\
& \text { INFL=1.NOM also=PL=PL 3.ACC-see } \\
& \text { 'We also saw them.' } \\
& \text { b. "hẽn=wa "kê=aj s-õmu } \\
& \text { INFL=1.NOM also=PL 3.ACC-see } \\
& \text { 'We also saw them / We also saw him / I also saw them.' }
\end{aligned}
$$

Another consequence of stress lapse avoidance is reported by Nonato. Both the clausal coordinating particle and the nominative pronouns are clitics. As with the previous examples, both clitics may appear when intervening material is present (37a). Moreover, if the pronoun is ergative, it is not a clitic, it is stressed, and may appear adjacent to the coordinating clitic $(37 \mathrm{~b}) .^{5}$
a. [Canarana mã =n=ka "pâj] $[=$ ne wâtâ ka"pẽrẽ =n=ka
Canarana $\mathrm{to}=\mathrm{INFL}=2 . \mathrm{NOM}$ arrive $][=$ and.ss what language $=\mathrm{INFL}=2 . \mathrm{NOM}$ s-arẽ?]
3.ACC-say]

'You went to Canarana and what language you spoke there?'
b. [[i-"pôt $] \quad[=$ nhy "kare $\varnothing$-khuru $]]$ mã
[[1.ABS-arrive $]]$ [=and.DS.3 2.ERG 3.ABS-eat]] FUT

'I will arrive and (then) you will eat it.'

The nominative pronoun deletes under adjacency to the coordinating particle.

$$
\begin{aligned}
& \text { a. *hẽn }[=\text { ka "pâj] }[=\text { ne }=\text { ka s-arẽ }] \\
& \text { INFL }[=2 . \text { NOM arrive }][=\text { and.SS }=2 . \text { NOM 3.ACC-say }] \\
& \text { 'You arrived and (then) you said it.' } \\
& \text { b. hẽn [=ka "pâj] [=ne s-arẽ }] \\
& \text { INFL }[=2 . \text { NOM arrive] [=and.SS 3.ACC-say] } \\
& \text { 'You arrived and (then) you said it.' }
\end{aligned}
$$

\footnotetext{
$\overline{{ }^{5} \mathrm{SS}}=$ same subject, i.e., the coordinating particle which is used when the subject of both conjuncts are the same. For mismatched subjects, and.DS (DS = different subjects) is used. Nonato reports that in addition to ergative pronouns, the absolutive pronouns, being prefixal, also do not delete when adjacent to a coordinating clitic.
} 
Finally, we note yet a third repair strategy for prosodic requirements on clitic placement, which is the absence of a repair. Descriptively, the alternation between Bulgarian and Macedonian with respect to their pronominal clitics is a case of repair/no-repair. However, Franks \& Bošković (2001) provide compelling evidence that the clitics in those languages are sensitive to syntactic properties and hence are undergoing syntactic movement. Although we do not have direct data, we will mention the corpus study by Riese (1984) for Northern Mansi (Vogul). The language has a conditional enclitic $=k e$, and based on the study of 223 conditional sentences, $67 \%$ of them had the conditional clitic appear immediately preverbally, $21 \%$ in other locations that the author believes to be conditioned pragmatically, and $12 \%$ in a verb-only conditional clause enclitic to the verb. Northern Mansi may fall in line with the Tobler-Mussafia and related languages in having syntactic movement of the clitic, but it is worth pursuing the possibility that this is an instance where a violation of a prosodic requirement is preferred over any other repair.

\subsection{Verb doubling as a post-syntactic operation}

As we noted, multiple cases of verb doubling constructions involving focus have had syntactic analyses advanced for them. We have proposed that verb doubling may also arise postsyntactically, as in Chechen and Ingush. Support for our proposal, then, would take the form of morphological verb doubling which is independent of a cliticization context. We claim that Breton exhibits such a pattern.

Breton is a Celtic language which has a V2 requirement in matrix clauses (Anderson 2005; Jouitteau 2012). The first position is typically used for topic or focus, but in the absence of such a target, expletive insertion or do support are applied instead. In a limited subset of verbs, which is also subject to dialect variation, the V2 condition may additionally be satisfied by verb doubling.

a. Initial focus/topic constituent

Avaloù a zebran

apples R eat.1SG

'I eat APPLES.'

b. Expletive insertion

Bez' ez an d' ar jardin

EXPL R go.1SG at the garden

'I am going into the garden.'

c. Do support

Debriñ a ran avaloù

eat $\quad \mathrm{R}$ do.1SG.PRES apples

'I eat apples.'

d. For a limited, idiosyncratic subset of verbs: verb doubling

Redek a redan bemdez

run.INF R run.1SG every.day

'I run every day.' 
e. Dont a zeuio re vraz ha re vihan... come.INF R come.FUT.3SG 3PL big and 3PL small

'The big ones and the small ones will come...'

As in the Chechen case, the doubling is not strongly linked to emphasis or focus. Jouitteau cites the idiosyncratic selection of verbs which license the verb doubling as another argument for the doubling process to take place in the post-syntactic component. Jouitteau makes a stronger claim, that it applies in the morphological component and is insensitive to the phonology. Our analysis is amenable to this claim: we expect morphological verb doubling to apply for reasons independent of prosodic or cliticization considerations.

To summarize, we have found a number of instances where various aspects of the Chechen and Ingush phenomenon - verb doubling, prosodic sensitivity of clitics, and the mobility of clitics - have been independently attested in unrelated languages. We take this to be support that the data in Chechen and Ingush fall in line with such general principles, and that its relatively unique profile is due to the interaction of these principles in the post-syntactic component.

\section{Conclusion}

We have presented a preliminary analysis of the Chechen and Ingush coordinating clitic ' $a$ and its associated verb doubling construction that is largely driven by prosodic considerations. We claimed that the construction in Chechen and Ingush are sufficiently different from previous cases which have been claimed to be syntactically motivated, and that such analyses are difficult to adapt for the present case. Moreover, while ' $a$ appears in a number of contexts as a focus marker, the verb doubling and coordination construction lacks any semantic/pragmatic force of emphasis and is hence amenable instead to a morphophonological analysis.

The alternative that we presented made use of an articulated morphophonological component implemented under Wolf's Optimal Interleaving framework. By doing so, we were able to break down the analysis into separate components which saw independent support in cross-linguistic data. As a result, we claim that the approach is superior to the previous templatic analysis by Good (2005).

That said, there remain many unresolved points due to the absence of native speaker consultants. First, the differences between Ingush and Chechen require investigation. Second, as the analysis crucially relies on differences in phonological phrasing among the different contexts in which ' $a$ is used, acoustic data is necessary to confirm the claims made in previous grammars. In particular, while Nichols (2011) claims that phrasal stress is assigned to immediately preverbal objects and preverbal particles, she does not make such a claim for adverb $+\mathrm{V}$ constructions. As adverbs and other adjuncts cannot host the coordinating 'a, we would need a phrasal distinction to avoid appealing to syntactic differences between adjuncts and objects/preverbs. 


\section{References}

Anderson, Stephen R. 2005. Aspects of the theory of clitics. Oxford Studies in Theoretical Linguistics. Oxford University Press.

BošKović, ŽELJKo. 2001. On the nature of the syntax-phonology interface. Elsevier.

Cheng, Lisa Lai-Shen. 2007. Verb copying in Mandarin Chinese. The copy theory of movement, ed. by Norbert Corver and Jairo Nunes, 151-174. John Benjamins Publishing Company.

Conathan, Lisa, and JefF Good. 2001. Morphosyntactic reduplication in Chechen and Ingush. Proceedings of the Chicago Linguistics Society 36: The panels, ed. by Arika Okrent and John P. Boyle, 49-61.

Cysouw, Michael. 2005. Morphology in the wrong place: A survey of preposed enclitics. Morphology and Its Demarcations, ed. by Wolfgang U. Dressler, Dieter Kastovsky, Oskar E. Pfeiffer, and Franz Rainer. John Benjamins Publishing Company.

EMBICK, DAvid, and Rolf Noyer. 1999. Locality in post-syntactic operations. MIT Working Papers in Linguistics 34: Papers on Morphology and Syntax, Cycle Two, ed. by Vivian Lin, Cornella Krause, Benjamin Bruening, and Karlos Arregi.

Franks, Steven, and Želuko BošKović. 2001. An argument for multiple Spell-Out. Linguistic Inquiry 32.174-183.

Ghomeshi, Jila; Ray Jackendoff; Nicole Rosen; and Kevin Russell. 2004. Contrastive focus reduplication in English (The salad-salad paper). Linguistic Inquiry 22.307357.

Good, JefF. 2005. A phrasal template and phrasal NDEB: The case of the Chechen core verb phrase. Ms., Max Planck Institute for Evolutionary Anthropology.

Jeschull, Liane. 2004. Coordination in Chechen. Coordinating constructions, ed. by Martin Haspelmath, 241-265. John Benjamins.

Jouitteau, MÉlanie. 2012. Verb doubling in Breton and Gungbe. The morphosyntax of reiteration in creole and non-creole languages, ed. by Enoch O. Aboh, Norval Smith, and Anne Zribi-Hertz. John Benjamins.

Kandybowicz, Jason. 2008. The grammar of repetition. John Benjamins.

Kimper, Wendell. 2008. Syntactic reduplication and the spell-out of movement chains. Ms., University of Massachusetts, Amherst.

Klavans, Judith L. 1985. The independence of syntax and phonology in cliticization. Language 61.95-120.

Klavans, Judith L. 1995. On clitics and cliticization. Garland. 
Koopman, Hilda. 1984. The syntax of verbs. Foris.

Mavrogiongos, Marios. 2013. Enclisis at the syntax-PF interface. Challenging clitics, ed. by Christine Meklenborg Salvesen and Hans Petter Helland, 27-54. John Benjamins Publishing Company.

Mussafia, Alfredo. 1888. Enclisi o proclisi del pronome personale atono quale oggeto. Romania 27.145-146.

Nichols, Joanna. 2011. Ingush grammar. University of California Press.

Nonato, Rafael. 2013. Clitic deletion and the morphology/phonology interface. Ms., Massachusetts Institute of Technology, lingbuzz/001911.

Nunes, JaIRo. 2004. Linearizaton of chains and sideward movement. MIT Press.

Peterson, David A. 2001. Ingush 'a: The elusive type 5 clitic? Language 77.144-155.

Riese, Timothy. 1984. The conditional sentence in the ugrian, permian and volgaic languages. Verband der wissenschaftlichen Gesellschaften Osterreichs.

Spencer, Andrew, and Ana R. Luís. 2012. Clitics: An introduction. Cambridge Textbooks in Linguistics. Cambridge University Press.

ToBler, Adolf. 1875. Vermischte beiträge zur französischen grammatik: Erste bis fünfte reihe. Leipzig: S Hirzel.

WaCKernagel, JaCoB. 1892. Über ein Gesetz der indo-germanischen Wortstellung. Indogermanische Forschungen 1.333-436.

Wolf, MatThew. 2008. Optimal interleaving: Serial phonology-morphology interaction in a constraint-based model Doctoral dissertation, university of massachusetts, amherst. 